\title{
Article \\ A Technology Acceptance Model-Based Analytics for Online Mobile Games Using Machine Learning Techniques
}

\author{
Shaifali Chauhan ${ }^{1}$, Mohit Mittal ${ }^{2, *(\mathbb{D})}$, Marcin Woźniak ${ }^{3, *(\mathbb{D}}$, Swadha Gupta ${ }^{4}$ and Rocío Pérez de Prado ${ }^{5}$ (D) \\ 1 Prestige Institute of Management, Gwalior 474020, India; shaifali.chauhan@prestigegwl.org \\ 2 Centre de Recherche en Informatique, Signal et Automatique de Lille, INRIA, \\ 59655 Villeneuve-d'Ascq, France \\ 3 Faculty of Applied Mathematics, Silesian University of Technology, 44100 Gliwice, Poland \\ 4 Department of Computer Science and Engineering, Thapar Institute of Engineering and Technology, \\ Patiala 147004, India; sgupta_phd18@thapar.edu \\ 5 Telecommunication Engineering Department, University of Jaén, 23071 Jaén, Spain; rperez@ujaen.es \\ * Correspondence: mohitmittal@ieee.org (M.M.); marcin.wozniak@polsl.pl (M.W.)
}

Citation: Chauhan, S.; Mittal, M.; Woźniak, M.; Gupta, S.; Pérez de Prado, R. A Technology Acceptance Model-Based Analytics for Online Mobile Games Using Machine Learning Techniques. Symmetry 2021, 13, 1545. https://doi.org/10.3390/ sym13081545

Academic Editor: Tomohiro Inagaki

Received: 21 July 2021

Accepted: 16 August 2021

Published: 23 August 2021

Publisher's Note: MDPI stays neutral with regard to jurisdictional claims in published maps and institutional affiliations.

Copyright: (c) 2021 by the authors. Licensee MDPI, Basel, Switzerland. This article is an open access article distributed under the terms and conditions of the Creative Commons Attribution (CC BY) license (https:// creativecommons.org/licenses/by/ $4.0 /)$.

\begin{abstract}
In recent years, the enhancement in technology has been envisioning for people to complete tasks in an easier way. Every manufacturing industry requires heavy machinery to accomplish tasks in a symmetric and systematic way, which is much easier with the help of advancement in the technology. The technological advancement directly affects human life as a result. It is found that humans are now fully dependent on it. The online game industry is one example of technology breakthrough. It is now a prominent industry to develop online games at world level. In this paper, our main objective is to analyze major factors which encourage mobile games industry to expand. Analyzing the system and symmetric relations inside can be done into two phases. The first phase is through a TAM Model, which is a very efficient way to solve statistical problems, and the second phase is with machine learning (ML) techniques, such as SVM, logistic regression, etc. Both strategies are popular and efficient in analyzing a system while maintaining the symmetry in a better way. Therefore, according to results from both the TAM model and ML approach, it is clear that perceived usefulness, attitude, and symmetric flow are important factors for game industry. The analytics provide a clear insight that perceived usefulness is an important parameter over behavior intention for the online mobile game industry.
\end{abstract}

Keywords: mobile games; TAM model; SVM; logistic regression; ridge regression; machine learning.

\section{Introduction}

Technology plays a vital role in a human being's life. In the past two decades, advancements in technology and increases in usage have hiked exponentially [1,2]. This began when the Internet was introduced to the whole world, which interconnects continents to each other. Due to this, communication has become easier and faster. The networking and communication field is still at top priority for research. With one click, a person can search information, communicate to other person via sending messages, calling, etc. [3]. After a lot of research efforts, a drastic change came in the mobile industry after the launching of smartphones. A lot of different companies and industries are doing rigorous research in improving technology and making services easily available for the humans $[4,5]$. The lifestyle of people also changed after the introduction of smartphones. People are now dependent on the Internet as everything is available on various applications [6,7]. The outsourcing companies, e-commerce companies, and online social media have gained a lot of attention. People are exploring more and more over their smartphones, such as paying bills [8], ordering the food [9], play games for entertainment [10], watching videos [11], etc. People, from the young generation to the older generation, are using smartphones, which are easy to understand and learn to use $[12,13]$. The big impact seen in the past few years 
is that on online game industry. Online games are more popular day by day [14]. Young people are more attracted to various online mobile games [15], such as PubG [16], WeChat games [17,18], Temple run [19], Candy Crush [20], etc.

According to today's scenario, the online mobile game industry and social media industry are in profit [21]. Mobile platforms convince people to connect to other people from other part of the globe. Social networking is not only limited to the talk and chatting but also helps in learning process, as well as inculcates more symmetry to life. Classes conducted by teachers, conferences, and meetings are very easy to attend by sitting at your home [22]. Many applications have been developed, such as the zoom meeting, Google meets, Microsoft teams, Skype, etc. [23]. All of these applications can accommodate hundreds of people at a time $[24,25]$. People are now up to date on news related to politics, technology [26], fashion, events, etc.

The popularity of online mobile games is increasing as the adaptability of technology access by young people is high [27]. A notable number of techniques have been applied to evaluate the behavior patterns. From the past techniques, the technology acceptance model (TAM) is one popular model which gained a lot of attention based on its ease of use and applications. According to researchers, classic TAM and its extended version are applied in many information technology systems. There are a large number of parameters that exist in the TAM model, such as ease of use and usefulness, which directly influence the adaptability of the new information system. Along with basic parameters, there are other parameters present which provide the platform for online games that can judge on a popularity basis. Already, some researchers have explored the area of social media and online gaming and provided analyses. For instance, D.-H. Shin and Y.-J. Shin focused on parameters which analyze the user's intentions for online games [28]. Lin and Lu suggested a model that works on motivation theory and tried to find out why people are interested in use of social networks [29].

In our research paper, we will investigate the major factors in the online game industry for gaining the popularity. This can be done by evaluating the factors based on an extended TAM model. A step forward to this, we will further investigate that how these factors give impressions based on machine learning techniques.

\section{Contribution}

The main contributions are as follows:

1. First, symmetric data is collected based on the questionnaire from a specified locality of India.

2. After the collection of data, based on hypothesis, the TAM model is implemented with the help of AMOS.

3. With the help of AMOS, it identifies the significant symmetric path coefficients between the primary factors.

4. A detailed result analysis of the TAM model is performed, giving insight to justification of the hypothesis proposed.

5. For further analysis, various symmetric ML techniques, such as logistic regression, SVM, etc., are applied on the same dataset to analyze the proposed hypothesis for encouraging predictive analysis.

6. The results for the main factor's predictions are compared with various implemented techniques. Last, we conclude our paper based on the objective.

The rest of the paper is assembled as follows. In Section 2, we define the basic TAM model. In Section 3, a detailed literature reviews is given, along with the hypothesis. In Section 4, we will provide the research methodology, including data analysis. Section 5 gives a brief introduction to machine learning approaches. In Section 6 is the detailed metric and result analysis based on the machine learning technique. Section 7 is focused on the discussion and limitation of the study. In the last section, Section 8 , the conclusion of the paper will be given, along with future aspects of the study. 


\section{Brief Introduction to TAM Model}

Information Technology (IT) has engulfed a lot of fields in which researchers are continuously traversing to find practical systems for the user. There exist many IT models which need to be fixed and enhanced in their performances, such as Technology Acceptance Model [30], Motivational Model [31], Theory of Reasoned Action [32], Model of Personal Computer Usage [33], Theory of Planned Behavior [34], and Unified Theory of Acceptance and Use of Technology [35]. However, over the past few decades, TAM has been successfully extended in many research disciplines and has given relevant implementations, exemplifying its potential significance to understand the user behavior towards adopting information technology systems. At the early stage of the TAM model, the actual system usage can be predicted by stimulation of innovative ideas and analyzing specific effects on the external variable, such as system features, capacities, etc. [30]. It is also proposed that user encouragement is comprised of three aspects that can explain actual system usage: perceived ease of use, perceived usefulness, and attitude. In this model, the attitude was used to determine the perceived usefulness and ease of use, which seems to be the strongest predictor for a user to approve or refuse a system. In addition, many external variables influence perceived usefulness and ease of use. Further, Reference [30] proposed that perceived usefulness and ease of use are the most significant values for each user to determine, either to support the system or not. Although the TAM model was the first proposed model which has been progressively modified by including many other parameters, such as behavioral intention (BI), which is added to the basic model of the TAM [36]. Since then, it has emerged as a leading model in the understanding of adoption of an IT system, and it is also considered the most suitable to examine the popularity of online games.

Online gaming has become one of the most potential benefits for the development of IT systems. As gaming requires high-end graphics and high-speed Internet to play online games with other players, the IT industry has begun to tackle complex problems to solve graphics problems and provide a smooth, reliable, and robust system. It has significantly changed the behavioral pattern of all users in utilizing their leisure time [37], not only in teenagers, but even in elderly people [38]. Moreover, with information technology, mobile online games are becoming much more influential than PC games as it is easy to carry a smartphone, rather than a PC, so people spend most of the time on smartphones. So, people play online games on their mobile device more frequently as compare to PC during traveling, etc. This has contributed to a great deal of work to grasp online games' success. In Reference [39], attempts to discuss success of online games generates from a fun-oriented technological perspective, by implementing social influences and flow experience as beliefsrelated constructs in a TAM model to anticipate acceptance by the users. In Reference [40], it is concluded that flow experience is much more essential than enjoyment for influencing the adoption of mobile online games by customers. Furthermore, the study revealed gender as a main moderator for mobile online game. Afterward, Reference [31] developed a generic research model that includes flow, social interaction, and enjoyment, based on the TAM model, which identifies the reasons that attract people to playing online games. In Reference [41], it is also indicated that confidence is another leading factor for online mobile games.

\section{Literature Review}

The proposed model is the based on the standards of the TAM model. This proposed model is considered for online games.

\subsection{Social Interaction}

Today, social interaction is considered as an important factor for the growth of online game business. Social interaction involves two or more entities with a sort of behavior. It is primarily divided into two categories in earlier research. First is user-system interaction; the second is user-to-user interaction [42]. In this research, we emphasize social networks, 
which rely on user-to-user engagement, generally called social engagement. Online games are designed to be fun and generate feelings of happiness which are then shared via existing social media platforms and websites. On social media, people can play games on the same site, allowing them to exchange results. In addition, people can give life to friends as a gift during game, which causes stronger bonds. Therefore, on the basis of above discussion, the mentioned hypothesis is framed:

Hypothesis 1. (H1) Social interaction contributes a significant effect on use context towards online games.

Hypothesis 2. (H2) Social interaction contributes a significant effect on perceived enjoyment towards online games.

\subsection{Use Context}

The context of use was not just a time or a place for a specific measure. It also leads to the circumstances and social situations [43]. Although a smartphone seems to be an everyday necessity in an individual's life, consumers can have a favorable perception towards a technology if it falls into a certain context of usage. Contextual considerations can be incorporated into the standard of the TAM model, to understand the user acceptance for online mobile applications. According to prior studies, it has attempted to fit the use context in order to expand the model. According to Reference [44], the acceptance for E-payments depends on some contextual parameters, such as identifying the lack of several other methods of payment. Since several contextual factors directly influence user acceptance, this research consists of two aspects which are strongly related to online games, such as the location of the users and their emotions. For instance, while traveling via public transport services, people feel bored, so it is not feasible to use a laptop or tablet, although there is space available for a smartphone. People can enjoy quality time while playing online smartphone games. Hence, the hypotheses are stated as follows:

Hypothesis 3. (H3) Use context contributes a significant effect on perceived enjoyment towards online games.

Hypothesis 4. (H4) Use context contributes a significant effect on perceived ease of use towards online games.

\subsection{Technology Acceptance Model}

Online mobile games are fun and enjoyment-based services, so Ease of use will help to indicate how frequently one can play a online game. A high perceived ease of use (PEU) result means that it is easy to start playing online games, as well as easy to recognize the rule for that. Perceived usefulness (PU) is a central structure in the TAM model. Therefore, various innovations have been modified and enhanced [45]. This paper explains PU of players in the real-world, which experience online games. On the other hand, Perceived enjoyment $(\mathrm{PE})$ is the degree to which a behavior is assumed to be pleasant and enjoyable without any effect [30]. It is an essential motive which refers to enjoyment and behavior of satisfaction [46]. In Reference [47], it is confirmed that PE has an important and optimistic effect on the attitude of online game players and their willingness to follow the online game's website. In addition, an analysis on the factors for online games related to the wireless networking world for Internet services is also accomplished. In Reference [48], it is found that the PE ought to be an attribute of gaming and perceptual enjoyment which should be taken into consideration in gaming research and practice. However, online gaming is indeed a cognitive process on the social media network. According to a previous study, flow was described as a holistic involvement while contributing in an action [49]. It has been used widely in such a variety of situations, such as sports, buying goods, mountain climbing, performing, and playing, due to the massive uncertainty and inter-dimensionality of the flow [50,51]. In Reference [52], authors claimed that flow has 
been determined by pleasure and determination. Therefore, that perceived behavioral control and challenges can forecast by flow. Reference [53] explained the four dimensions of flow, which was discussed in past research: focused control, power, fascination, and linguistic dissociation. Moreover, flow is based on curiosity in this review. Curiosity describes a situation where people remain excited about the method and attempt to gain technical skill while implementing action, which states that users are highly interested in use of the Internet, so that they can learn via existing and new knowledge, as well as information [54]. However, smartphone online games are not only for playing games; they also build competition and influence people to spend time with their friends. It also helps to retain the interest of players, which leads to the desire for replays.

Therefore, we have formulated the necessary hypotheses:

Hypothesis 5. (H5) Perceived ease of use contributes a significant effect on perceived usefulness towards online game.

Hypothesis 6. (H6) Perceived enjoyment contributes a significant effect on perceived usefulness towards online games.

Hypothesis 7. (H7) Perceived enjoyment contributes a significant effect on flow towards online games.

Hypothesis 8. (H8) Perceived usefulness contributes a significant effect on attitude towards online games.

Hypothesis 9. (H9) Perceived enjoyment contributes a significant effect on attitude towards online games.

Hypothesis 10. (H10) Attitude contributes a significant effect on behavioral intention towards mobile games.

Hypothesis 11. (H11) Flow contributes a significant effect on behavioral intention towards online games.

Hypothesis 12. (H12) Perceived usefulness contributes a significant effect on behavioral intention towards online games.

Based on the proposed hypothesis, a TAM-based model is designed and represented graphically in Figure 1. The main building blocks for the proposed system implemented are shown in Figure 2.

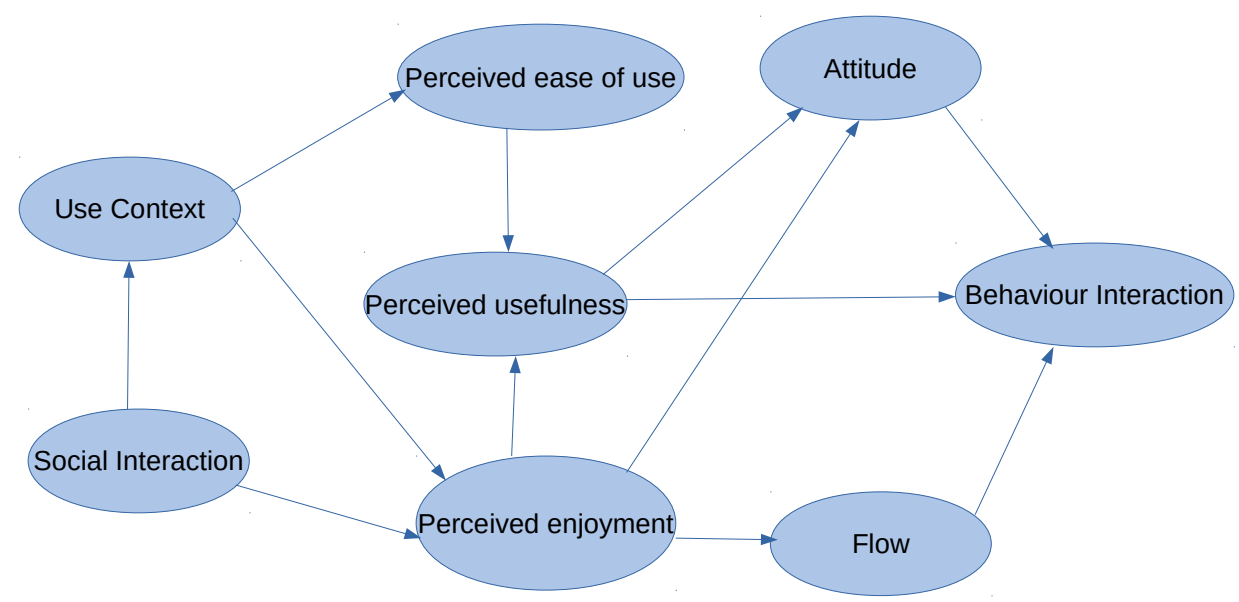

Figure 1. Hypothesis-based TAM model. 


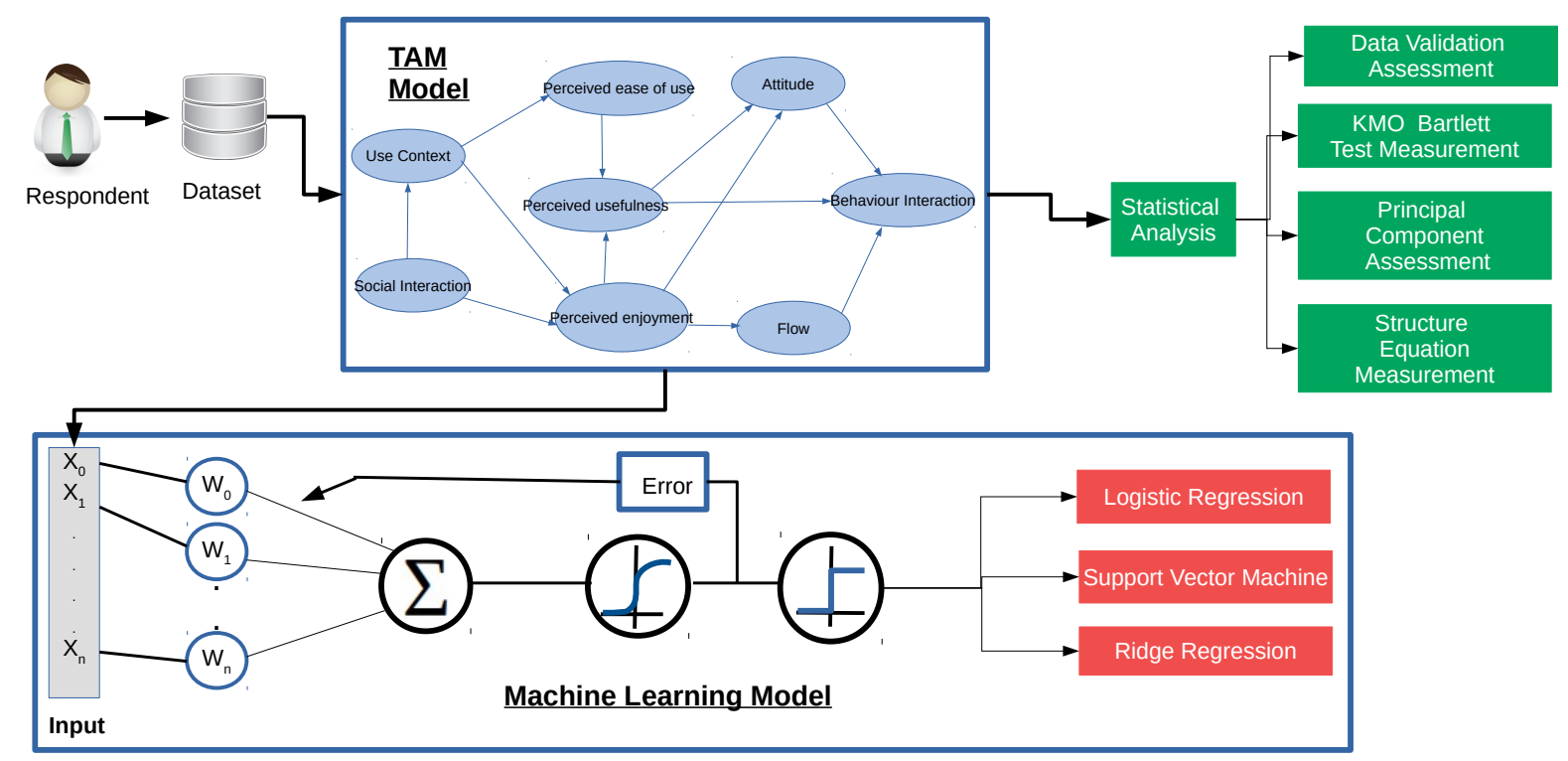

Figure 2. The building blocks for the proposed system.

\section{Research Methodology}

An inclusive literature review shows that previous studies have highly accepted the survey methodology. The quantitative result of any investigation leaned entirely on the knowledge and skills of the respondents in online games. For the present analysis, empirical research was employed, and data were collected using a similar survey approach. The survey was completed by respondents who are involved in online games, mostly from three cities in the Central Zone of India (i.e., Agra, Gwalior, and Indore). The initial questionnaire was divided into two sections. The first section had two questions, used to gather the demographic information, such as gender and age. All questions are made to maintain symmetry in data. The second section of the questionnaire contained a major component with 23 items to explore the 8 factors discussed in the theoretical model. Each question was evaluated on a 7-point Likert scale with "strongly disagree (1), strongly agree (7)" endpoints. The content validity of the questionnaire is mentioned in Table 1 . The data were collected as non-probability purposive sampling method, in which 450 questionnaires were distributed in central India (i.e., Agra, Gwalior, and Indore), between the age group of 16 to 35 years of age; out of those, 304 data samples were used for further analysis. The collected data was analyzed through various tools and techniques, such as SPSS, used for descriptive statistics of male and female. Along with the KMO tested, a rotation matrix was also tested by principal component method, and AMOS 18 Tools were used for CFA and SEM to test the framed hypothesis. In addition to statistical analysis, to find more robust results, machine learning was used, in which various methods were executed.

Table 1. Content validity of questionnaire.

\begin{tabular}{ccc}
\hline S.No & Construct & Questionnaire Source \\
\hline 1 & Use Context & {$[55]$} \\
2 & Social Interaction & {$[56]$} \\
3 & Perceived ease of use & {$[45]$} \\
4 & Perceived usefulness & {$[57]$} \\
5 & Perceived enjoyment & {$[57]$} \\
6 & Attitude & {$[48]$} \\
7 & Flow & {$[48]$} \\
8 & Behavior intention & {$[46]$} \\
\hline
\end{tabular}




\subsection{Data Analysis}

In descriptive statistics, the categorical data was examined, in which we evaluated online games' users. Hence, Table 2 presents the users, i.e., age group from 16 to 20 years old, and people who are more involved in online games, in which 132 total respondents are involved in this category, where 102 were male, and 30 were female. Similarly, in another category, of 21 to 25 years old, the total of respondents was 90 , in which there were 48 males and 42 females. Next, in the 26 to 30 age group, the total was 54, with 37 males and 17 females. At last, in the age group of 31 to 35 year old people, the total number was 28 , in which 20 were male, and 8 were female. Therefore, the total number of respondents was 304, in which 207 were male, and 97 were female. In Figure 3, the percentage of males and females who participated is represented.

Table 2. Descriptive analysis.

\begin{tabular}{cccc}
\hline Age Group & Male & Female & Total \\
\hline $16-20$ & 102 & 30 & 132 \\
$21-25$ & 48 & 42 & 90 \\
$26-30$ & 37 & 17 & 54 \\
$31-35$ & 20 & 8 & 28 \\
Total & $\mathbf{2 0 7}$ & $\mathbf{9 7}$ & $\mathbf{3 0 4}$ \\
\hline
\end{tabular}

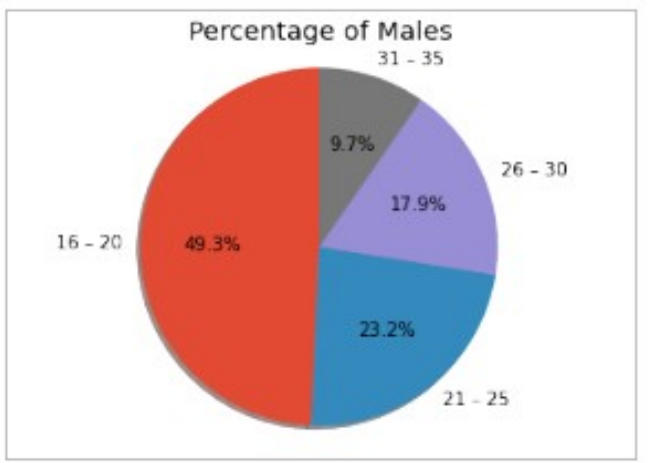

(a)

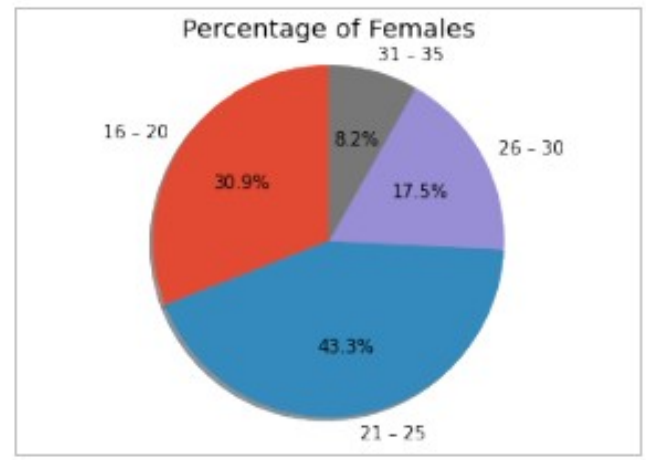

(b)

Figure 3. Piechart representation for males and females of different ages involved in percentage.

Next, to evaluate and validate the originality of data, the first method was implemented to conduct data standardization. In this process, we measured the average (Avg) and standard deviation (SD) of all latent variables result and the average for each item; Table 3 displays the results in that the average of all factors is above 5; therefore, these assumptive constructs are standard. In addition to the analysis, the Cronbach's alpha value was demonstrated to determine the internal consistency and convergent validity of the latent variables mentioned below in Table 3, also represented graphically in Figure 4. 
Table 3. Data validation assessment.

\begin{tabular}{|c|c|c|c|c|c|c|}
\hline S.No & Latent Variables & Items & Avg & SD & Avg & Cronbach \\
\hline & & UC1 & 6.13 & 0.844 & & \\
\hline \multirow[t]{3}{*}{1} & Use Context & UC2 & 6.05 & 0.951 & 5.73 & 0.798 \\
\hline & & UC3 & 5.01 & 0.956 & & \\
\hline & & SI1 & 5.89 & 0.934 & & \\
\hline \multirow[t]{3}{*}{2} & Social Interaction & SI2 & 5.68 & 1.08 & 5.76 & 0.788 \\
\hline & & SI3 & 5.72 & 1.076 & & \\
\hline & & PEU1 & 5.83 & 0.766 & & \\
\hline \multirow[t]{2}{*}{3} & Perceived ease of use & PEU2 & 6.06 & 0.778 & 5.94 & 0.871 \\
\hline & & PU1 & 5.37 & 1.32 & & \\
\hline \multirow[t]{3}{*}{4} & Perceived usefulness & PU2 & 5.42 & 1.143 & 5.35 & 0.719 \\
\hline & & PU3 & 5.27 & 1.312 & & \\
\hline & & PE1 & 5.77 & 0.988 & & \\
\hline \multirow[t]{3}{*}{5} & Perceived enjoyment & PE2 & 5.87 & 0.910 & 5.87 & 0.748 \\
\hline & & PE3 & 5.90 & 0.967 & & \\
\hline & & ATT1 & 5.88 & 0.957 & & \\
\hline \multirow[t]{3}{*}{6} & Attitude & ATT2 & 5.86 & 0.928 & 5.87 & 0.787 \\
\hline & & ATT3 & 5.87 & 0.938 & & \\
\hline & & FL1 & 5.31 & 1.256 & & \\
\hline \multirow[t]{3}{*}{7} & Flow & FL2 & 5.6 & 1.045 & 5.47 & 0.729 \\
\hline & & FL3 & 5.52 & 1.158 & & \\
\hline & & BI1 & 5.89 & 0.96 & & \\
\hline \multirow[t]{2}{*}{8} & Behavior intention & $\mathrm{BI} 2$ & 6.13 & 0.96 & 5.97 & 0.737 \\
\hline & & $\mathrm{BI} 3$ & 5.90 & 1.10 & & \\
\hline
\end{tabular}

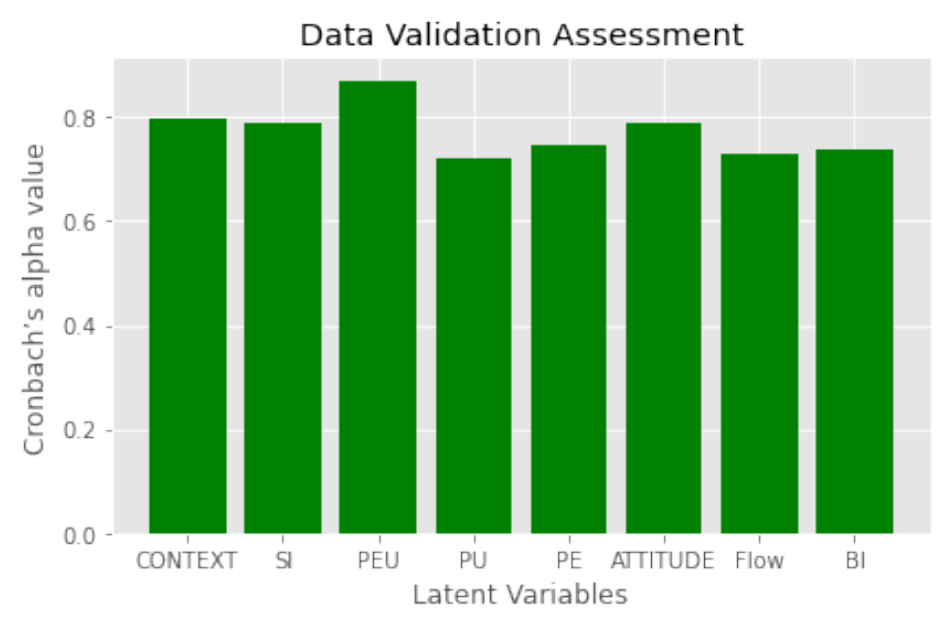

Figure 4. Graphical representation of Cronbach's alpha value.

In addition to reliability and validity of data, the discriminant validity measurement is very important for symmetric construct valuation. It is shown by evidence of systemic indicators which, logically, should not be very closely related or, in fact, not be proven to be strongly correlated. However, the values of all constructs and their level of correlation and symmetry are mentioned in Table 4 . Therefore, the values were found to be appropriate in study. 
Table 4. Discriminant validity measurement.

\begin{tabular}{ccccccccc}
\hline Latent Variable & UC & SI & PEU & PU & PE & ATT & FL & BI \\
\hline UC & 1 & & & & & & & \\
SI & 0.622 & 1 & & & & & & \\
PEU & 0.646 & 0.493 & 1 & & & & & \\
PU & 0.526 & 0.48 & 0.416 & 1 & & & & \\
PE & 0.54 & 0.488 & 0.563 & 0.293 & 1 & & & \\
ATT & 0.652 & 0.518 & 0.632 & 0.623 & 0.483 & 1 & & \\
FL & 0.562 & 0.453 & 0.476 & 0.612 & 0.373 & 0.596 & 1 & \\
BI & 0.656 & 0.518 & 0.617 & 0.563 & 0.512 & 0.688 & 0.637 & 1 \\
\hline
\end{tabular}

\subsection{Principal Component Assessment}

Table 5 displays two measurements, which demonstrate the consistency of the data for structural analysis.

Table 5. KMO Bartlett test measurement.

\begin{tabular}{ccc}
\hline & KMO and Bartlett & \\
\hline Kaiser-Meyer-Olkin (KMO) & & 0.934 \\
& Chi-square test & 4519.32 \\
Bartlett Testing & df & 324 \\
& Sig. & 0.000 \\
\hline
\end{tabular}

The KMO Test of Sampling Adequacy is a statistic that indicates the proportions of variation in the indicators which can be affected by the factors involved. Maximum levels (closer to 1) usually mean that a factor analysis can be beneficial for your results. When its minimum is more than 0.50 , the findings of the factor analysis are unlikely to be effective. A Bartlett test of the hypothesis that your matrix for correlation is an identity matrix suggests that your variables are unrelated and, thus, unsuitable for structural identification. Less than 0.05 of the level of significance reveals that a factor analysis may be appropriate for certain results. Therefore, the results of study, i.e., Kaiser-Meyer-Olkin $0.934, \chi^{2}$ value 4519.32 , df value 324 , which is significant at 0.000 , are supported as per the threshold criteria.

In continuing to follow the Principal Component Assessment method, the next process is to rotate the Principal Component Analysis matrix used in study to determine the influence of 8 variables. The results summarized the grade of 8 variables, via high to low, which are shown in Table 6.

Table 6. Rotation matrix measurement.

\begin{tabular}{ccccccccc}
\hline Constructs & $\mathbf{1}$ & $\mathbf{2}$ & $\mathbf{3}$ & $\mathbf{4}$ & $\mathbf{5}$ & $\mathbf{6}$ & $\mathbf{7}$ & $\mathbf{8}$ \\
\hline UC1 & 0.09 & 0.261 & 0.273 & 0.355 & $\mathbf{0 . 5 1 5}$ & 0133 & 0.032 & 0.237 \\
UC2 & 0.084 & 0.127 & 0.023 & 0.123 & $\mathbf{0 . 7 1 2}$ & 0.211 & 0.133 & 0.141 \\
UC3 & 0.157 & 0.117 & 0.378 & 0.125 & $\mathbf{0 . 6 6 5}$ & -0.011 & 0.112 & 0.17 \\
SI1 & 0.110 & 0.329 & $\mathbf{0 . 5 8 7}$ & 0.143 & 0.342 & 0.089 & 0.048 & 0.158 \\
SI2 & 0.236 & 0.146 & $\mathbf{0 . 7 2 4}$ & 0.269 & 0.08 & 0.159 & 0.198 & 0.076 \\
SI3 & 0.18 & 0.176 & $\mathbf{0 . 7 7 6}$ & 0.189 & 0.145 & 0.10 & 0.074 & 0.09 \\
PEU1 & 0.109 & 0.039 & 0.078 & 0.235 & 0.233 & 0.139 & 0.049 & $\mathbf{0 . 8 7}$ \\
PEU2 & -0.043 & 0.421 & 0.18 & 0.08 & 0.178 & -0.033 & 0.224 & $\mathbf{0 . 6 4 3}$ \\
PU1 & $\mathbf{0 . 7 7 6}$ & 0.138 & 0.232 & 0.098 & -0.009 & 0.244 & 0.312 & -0.011 \\
PU2 & $\mathbf{0 . 7 8 7}$ & 0.236 & 0.128 & 0.310 & 0.154 & 0.53 & -0.010 & -0.009 \\
PU3 & $\mathbf{0 . 8 3 7}$ & 0.119 & 0.187 & 0.156 & 0.183 & 0.112 & 0.0037 & 0.176 \\
\hline
\end{tabular}


Table 6. Cont.

\begin{tabular}{|c|c|c|c|c|c|c|c|c|}
\hline Constructs & 1 & 2 & 3 & 4 & 5 & 6 & 7 & 8 \\
\hline PE1 & 0.297 & 0.343 & 0.37 & 0.584 & 0.109 & 0.218 & 0.8 & -0.006 \\
\hline PE2 & 0.265 & 0.176 & 0.238 & 0.718 & 0.8 & 0.192 & 0.024 & 0.18 \\
\hline PE3 & 0.245 & 0.164 & 0.228 & 0.589 & 0.086 & 0.079 & 0.184 & 0.265 \\
\hline ATT1 & 0.15 & 0.616 & 0.131 & 0.381 & 0.157 & 0.188 & 0.475 & 0.152 \\
\hline ATT2 & 0.210 & 0.658 & 0.217 & 0.277 & 0.019 & 0.248 & 0.097 & 0.065 \\
\hline ATT3 & 0.179 & 0.567 & 0.159 & 0.341 & 0.225 & 0.009 & 0.164 & 0.146 \\
\hline FL1 & 0.175 & 0.127 & 0.145 & 0.117 & 0.029 & 0.852 & 0.56 & 0.026 \\
\hline FL2 & 0.235 & 0.291 & 0.183 & 0.156 & 0.231 & 0.78 & -0.134 & 0.176 \\
\hline FL3 & 0.374 & 0.273 & 0.182 & -0.087 & 0.133 & 0.670 & 0.039 & 0.126 \\
\hline $\mathrm{BI} 1$ & 0.234 & 0.365 & 0.227 & 0.318 & 0.342 & 0.62 & 0.512 & 0.110 \\
\hline $\mathrm{BI} 2$ & 0.112 & 0.065 & 0.157 & 0.076 & 0.475 & 0.067 & 0.645 & 0.184 \\
\hline $\mathrm{BI} 3$ & 0.359 & 0.072 & 0.243 & 0.303 & 0.224 & 0.19 & 0.547 & 0.085 \\
\hline
\end{tabular}

\subsection{Structure Equation Measurement}

In Structure Equation Measurement (SEM), the first measure is to find the association among independent and dependent variables by the model fit indices; eight fit indicators are used in this work, to test the proposed model and validate the proposed hypotheses, and the eight fit indicators are Chi-Square $\left(\chi^{2}\right)$, Goodness-of-Fit Index (GFI), Adjusted goodness of fit index (AGFI), Root Mean Square Error of Approximation (RMSEA), Root Mean Square Residual (RMR), Comparative Fit Index (CFI), Normed Fit Index (NFI), and Incremental Fit Index (IFI). The performance of eight indicators, and each performance measure appropriate in the research, is mentioned below in Table 7.

Table 7. Analysis of significance of path coefficient.

\begin{tabular}{|c|c|c|c|}
\hline Hypothesis & $\begin{array}{c}\text { Construct } \\
\text { Relationship }\end{array}$ & Estimate & Decision \\
\hline H1 & $\mathrm{SI} \longrightarrow \mathrm{UC}$ & $0.356^{* *}$ & Supported \\
\hline $\mathrm{H} 2$ & $\mathrm{SI} \longrightarrow \mathrm{PE}$ & 0.096 * & Supported \\
\hline $\mathrm{H} 3$ & $\mathrm{UC} \longrightarrow \mathrm{PE}$ & $0.0843^{* * *}$ & Supported \\
\hline $\mathrm{H} 4$ & $\mathrm{UC} \longrightarrow \mathrm{PEU}$ & $0.365^{* *}$ & Supported \\
\hline H5 & $\mathrm{PEU} \longrightarrow \mathrm{PU}$ & $0.0865 * * *$ & Supported \\
\hline H6 & $\mathrm{PE} \longrightarrow \mathrm{PU}$ & -0.023 & Not Supported \\
\hline $\mathrm{H7}$ & $\mathrm{PE} \longrightarrow \mathrm{FL}$ & $0.51 *$ & Supported \\
\hline H8 & $\mathrm{PU} \longrightarrow \mathrm{ATT}$ & $0.644^{* * *}$ & Supported \\
\hline H9 & $\mathrm{PE} \longrightarrow \mathrm{ATT}$ & -0.834 & Not Supported \\
\hline $\mathrm{H} 10$ & $\mathrm{ATT} \longrightarrow \mathrm{BI}$ & $0.853^{* * *}$ & Supported \\
\hline H11 & $\mathrm{FL} \longrightarrow \mathrm{BI}$ & $0.798^{* * *}$ & Supported \\
\hline H12 & $\mathrm{PU} \longrightarrow \mathrm{BI}$ & $0.958^{* * *}$ & Supported \\
\hline
\end{tabular}

The model was confirmed by different criteria of model fit indicators, such as the $\chi^{2}$ value, i.e., 1.745 , which was between 1 to 2 , indicating that the model was fit to the data. The goodness of fit index value was 0.877, which is acceptable as per threshold limit 0.9 [58], indicating that the model was appropriate for the data. Next, the adjusted goodness of fit index value was found to be 0.885 , which is higher than threshold limit, i.e., 0.80 . Hence, it is considered a well-fitting model. Now, the Root Mean Square Error of Approximation parameters is within the range of 0.05 to 0.10 , an indicator of good fit, and value beyond 0.10 suggested poor fit was considered [59]. Hence, the result found, i.e., 0.059, is as per criteria, which is acceptable in study. The outcome of the root mean square residual is 0.043 . Therefore, value as high as 0.08 are considered to be appropriate [60]. Next, the NFI is a cumulative measurement of goodness for a mathematical model that is not influenced by the numbers of specifications/constructs in the study. Goodness of fit is tested by a correlation between the study model and the model of completely uncorrelated constructs [61]; the value received in study is 0.895 . Hence, the result is favorable, as 
per threshold limit, and the results of NFI were evaluated with the help of the formula mentioned below.

$$
N F I=\Delta_{1}=1-\frac{\hat{C}}{\hat{C}_{b}}=1-\frac{\hat{F}}{\hat{F}_{b}} .
$$

Now, the value of Incremental Fit Index was measured to know the degree of freedom of the model. The alternative name of IFI is comparative [62] and relative fit indices [63]. Hence, the value is measured is 0.955 , which indicates that the results are supportive as per the statics criteria. The results are evaluated with the help of formula mentioned below:

$$
I F I=\Delta_{2}=1-\frac{\hat{C_{b}}-\hat{C}}{\hat{C}_{b}-d} .
$$

Lastly, the Comparative Fit Index (CFI) analyzes the good fit by investigating the difference between both, the data and the hypothesized framework, thus optimizing for the concerns of dataset found in the chi-squared fit test and NFI. Comparative fit index values vary between 0 and 1, with higher values suggesting good fit. Initially, a comparative fit index value of.90 or greater was considered to imply appropriate model fit. Therefore, the result found is 0.957 , which implies that outcome is as per threshold limit. The CFI value is calculated with the help of formula mentioned below.

$$
C F I=1-\frac{\max (\hat{C}-d, 0)}{\max \left(\hat{C_{b}}-d_{b}, 0\right)}=1-\frac{N C P}{N C P_{b}} .
$$

In addition to this, the objective of the path analysis is always to determine the reliability and validity of the hypothesis-based model and to calculate the complexity of the causal relationships among the variables. The structural equation model was tested by checking the hypothesized relationship between different factors, which is shown in Figure 5 and Table 7.

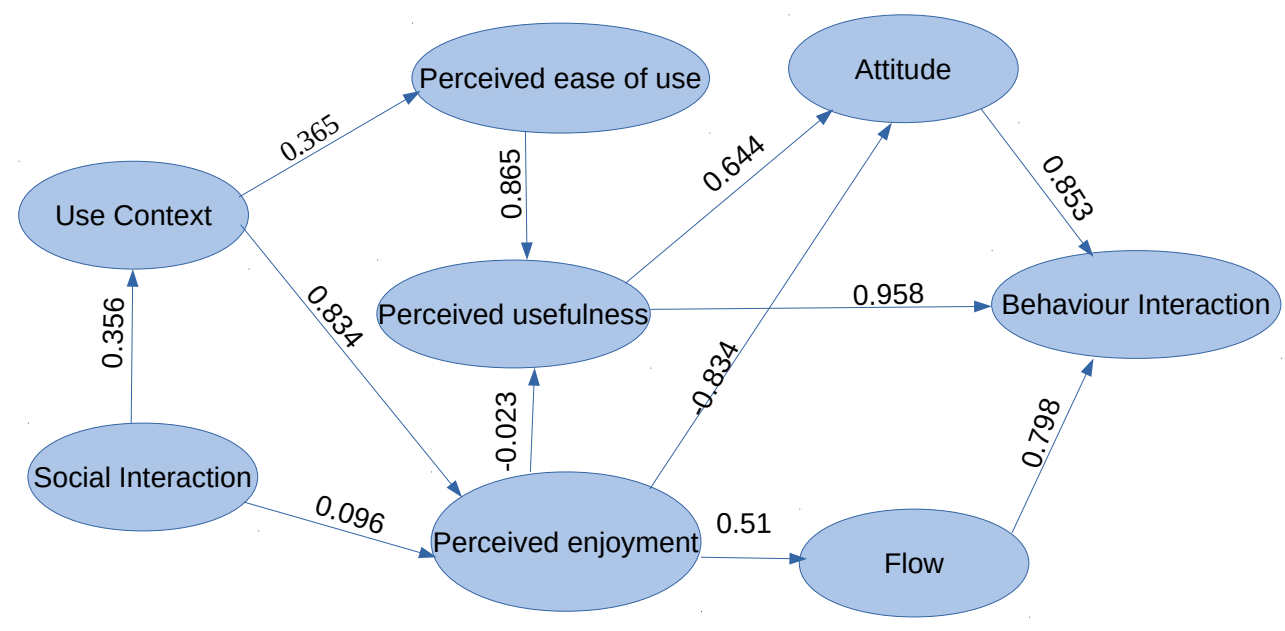

Figure 5. SEM model.

This study is framed by the Technology Assessment Model, which followed 12 symmetric assumptions among constructs. Table 7 justifies the same. Therefore, the relationship of hypothesis, i.e., $\mathrm{H} 3, \mathrm{H} 5, \mathrm{H} 8, \mathrm{H} 10, \mathrm{H} 11, \mathrm{H} 12$, results significant at $p<0.001$ is supported by many previous research studies $[28,64]$. On another hand, the symmetric relationship of the hypotheses, i.e., $\mathrm{H} 1$ and $\mathrm{H} 4$, are both significant at $p<0.01$. Hence, the outcome of $\mathrm{H} 1$ and $\mathrm{H} 4$ are supported by Reference [57]. Moreover, $\mathrm{H} 2$ and $\mathrm{H} 7$ are significant at $p<0.05$. Lastly, the results of $\mathrm{H} 6$ and $\mathrm{H} 9$ are insignificant in the study. 


\section{Machine Learning Techniques}

\subsection{Support Vector Machine}

Support vector machine (SVM) is under the category of supervised learning. The supervised learning means a target value is provided to tackle the problem and find-out the error rate. SVM is generally used for classification, as well as regression analysis [65]. The equation for SVM classifier is as follows:

$$
\left[\frac{1}{n} \sum_{i=1}^{n} \max \left(0,1-y_{i}\left(w \cdot x_{i}-b\right)\right)\right]+\lambda\|w\|^{2} .
$$

The kernel function exists for further evaluation of SVM, depending on the problem which can be linear, polynomial, rbf, and sigmoid type.

\subsection{Logistic Regression}

Logistic regression is one of the statistical models that is popular for complex problems. It has a function known as logistic function that is able to model a binary dependent variable [66]. In a mathematical point of view, a binary logistic regression depends on two existing values, i.e., 0 or 1 . The label value 1 represents a collection of one or more independent variables. The independent variable exists between 0 and 1, depending on logistic function. In the machine learning prediction problems, usually, sigmoid function is used for evaluation [67]. The mathematical equation is as follows:

$$
\operatorname{logistic}(\eta)=\frac{1}{1+\exp (-\eta)} .
$$

Based on the probability, the logistic regression between 0 and 1 related to classification. The output is as follows:

$$
\begin{gathered}
P\left(O^{(i)}=1\right)=\frac{1}{1+\exp \left(-\left(\beta_{0}+\beta_{1} x_{1}^{(i)}+\cdots, \beta_{n} x_{n}^{(i)}\right)\right)} \\
\log \left(\frac{P(y=1)}{1-P(y=1)}\right)=\log \left(\frac{P(y=1)}{P(y=0)}\right)=\beta_{0}+\beta_{1} x_{1}^{(i)}+\cdots, \beta_{n} x_{n}^{(i)} .
\end{gathered}
$$

The above equation is called a log odd function.

If one element, i.e., the $x_{j}$ attribute, is replaced, then it will effect on the prediction, such as:

$$
\left(\frac{P(y=1)}{1-P(y=1)}\right)=\text { odds }=\exp \left(\beta_{0}+\beta_{1} x_{1}^{(i)}+\cdots, \beta_{n} x_{n}^{(i)}\right) .
$$

Now, let us check if one of the feature value is raised to 1 .

$$
\begin{gathered}
\frac{\operatorname{odds}_{x_{j+1}}}{\text { odds }}=\frac{\exp \left(\beta_{0}+\beta_{1} x_{1}+\cdots \beta_{j}\left(x_{j}+1\right) \cdots, \beta_{n} x_{n}^{(i)}\right)}{\exp \left(\beta_{0}+\beta_{1} x_{1}+\cdots \beta_{j} x_{j} \cdots, \beta_{n} x_{n}^{(i)}\right)}, \\
\frac{\exp (a)}{\exp (b)}=\exp (a-b), \\
\frac{\text { odd } s_{x_{j+1}}}{\text { odds }}=\exp \left(\beta_{j}\left(x_{j+1}\right)-\beta_{j} x_{j}\right)=\exp \left(\beta_{j}\right) .
\end{gathered}
$$

Conclusively, we can say that one replacement in the feature can affect the ratio by an $\exp$ factor $\left(\beta_{j}\right)$. 


\subsection{Ridge Regression}

Ridge regression is famous technique that includes multiple regression analysis on the data [68]. The equation on which ridge regression is calculated is as follows:

$$
\alpha=\beta \underline{\mathbf{B}}+\underline{\mathbf{e}}
$$

where $\alpha$ denoted as dependent variable, $\beta$ denoted as independent variable, $\underline{\mathbf{B}}$ represented as regression coefficient that must be estimated, and $\underline{\mathbf{e}}$ provides the errors.

For regression coefficients, estimation is evaluated by equation as follows:

$$
\underline{\hat{\mathbf{B}}}=\left(\beta^{\prime} \beta\right)^{-1} \beta^{\prime} \alpha
$$

$\beta^{\prime} \beta=R$, where $\mathrm{R}$ represents the correlation matrix.

$$
E(\underline{\hat{\mathbf{B}}})=\underline{\mathbf{B}} .
$$

The co-variance matrix,

$$
V(\underline{\hat{\mathbf{B}}})=\sigma^{2} \mathbf{R}^{-1},
$$

we assumed as $\sigma^{2}=1$.

$$
V\left(\hat{\mathbf{B}}_{j}\right)=r^{j j}=\frac{1}{1-R_{j}^{2}} .
$$

Adding the small value of $\mathrm{k}$ :

$$
\underline{\tilde{\mathbf{B}}}=(\mathbf{R}+\mathbf{k I})^{-1} \beta^{\prime} \alpha .
$$

The amount of bias:

$$
E(\underline{\tilde{\mathbf{B}}}-\underline{\mathbf{B}})=\left[\left(\mathbf{f i}^{\prime} \mathbf{f i}+\mathbf{k I}\right)^{-\mathbf{1}} \mathbf{f i}^{\prime} \mathbf{f i}-\mathbf{I}\right] \underline{\mathbf{B}} .
$$

The covariance matrix:

$$
V(\underline{\tilde{\mathbf{B}}})=\left(\mathbf{f i}^{\prime} \mathbf{f i}+\mathbf{k I}\right)^{-\mathbf{1}} \mathbf{f i}^{\prime} \mathbf{f i}\left(\mathbf{f i}^{\prime} \mathbf{f i}+\mathbf{k I}\right)^{-\mathbf{1}} .
$$

\section{Machine Learning Result Analysis}

The machine learning techniques are very efficient in predicting the target factor based on embedded parameters. In this paper, various techniques have been selected that predict how much the level of selected parameters, such as perceived enjoyment and perceived ease of usefulness, are involved in expressing to grab the attention of the user for continuously playing online games. These parameters provide the credibility of online game usage and enhance skills. For the evaluation with machine learning techniques, there exist metrics, such as accuracy, precision, recall, and F1-measure. Before that, there is the need to evaluate the True Positive (TP), False Positive (FP), True Negative (TN), and False Negative (FN).

\section{- Accuracy}

The accuracy is calculated in terms of aforementioned factors as the ratio of data points $(\mathrm{TP}+\mathrm{TN})$ with total correct prediction, i.e., $(\mathrm{TP}+\mathrm{TN}+\mathrm{FP}+\mathrm{FN})$. Accuracy is the important measurement criteria which evaluates the performance of classification model. The equation is as follows:

$$
\text { Accuracy }=\frac{T P+T N}{T P+T N+F P+F N} .
$$

- Precision 
Precision is represented as the ratio of True Positive (TP) information to the combined True Positive (TP) and False Positive (FP) information. It gives the correctly classified information from the given information. The equation is as follows:

$$
\text { Precision }=\frac{T P}{T P+F P} .
$$

- Recall

Recall is calculated as ratio of True Positive (TP) information to the combined True Positive (TP) and False Negative (FN) information. The equation is as follows:

$$
\text { Recall }=\frac{T P}{T P+F N} .
$$

\section{- F1 Score}

F1 Score is calculated to harmonic mean of Recall and Precision. The F1 Score provides the proper and correct evaluation if the model's performance in classifying the perceived usefulness and perceived enjoyment. The equation of F1 Score calculation is as follows:

$$
\text { F1Score }=2 \times \frac{\text { Precision } \times \text { Recall }}{\text { Precision }+ \text { Recall }} .
$$

\subsection{Data}

The key role is performed by the various algorithms which indulge the dataset and provide the prediction performance. The dataset is divided into to symmetric parts as training set and test set. The training set is given initially to each algorithm to learn the data and its target output. If the data is cleaned, the prediction will be much more accurate; otherwise, we need to clean and remove the noise from it. The ration of training set and test set is $75 \%$ and $25 \%$, respectively. Then, after, one by one algorithm is used to evaluate the data and check performance. From Figure 6, the score percentage is calculated with three machine learning algorithms, such as SVM, logistic regression, and ridge regression. According to Tables 8 and 9 , it is shown that logistic regression provides very high accuracy and precision, which means logistic regression is a good predictor for the given problem.

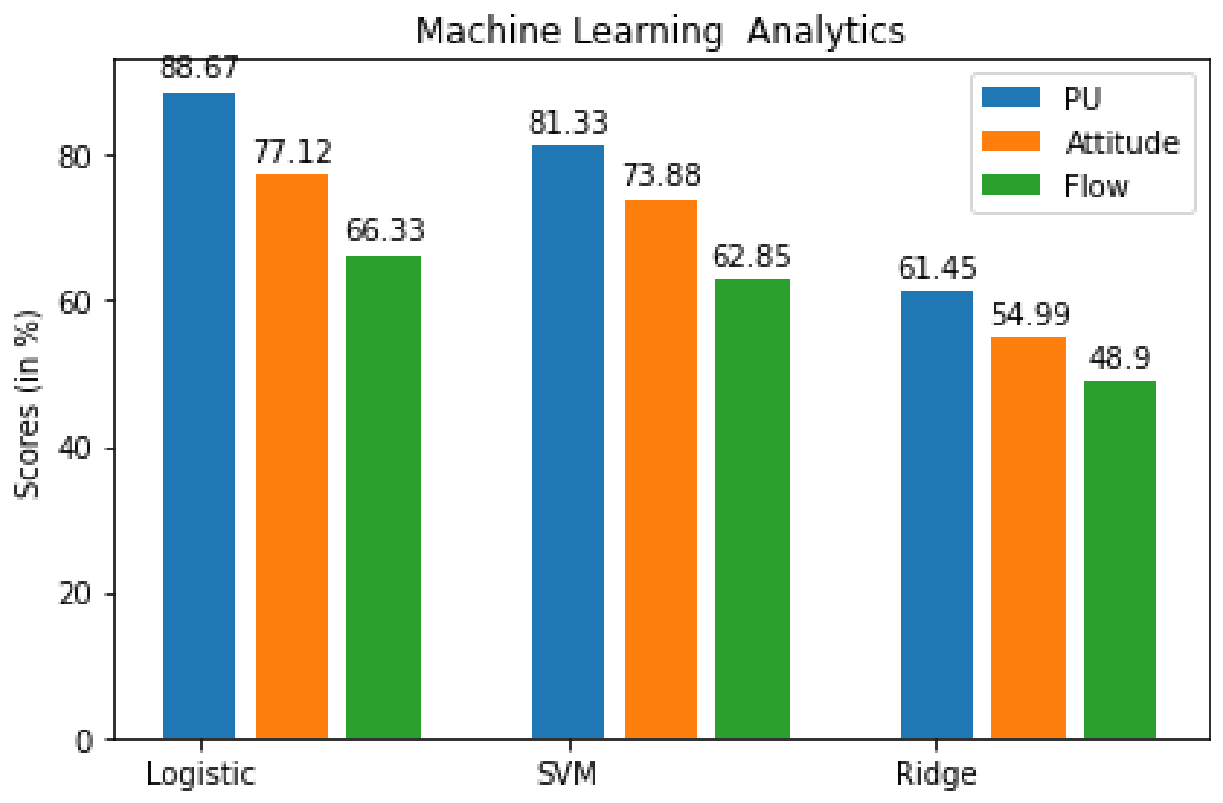

Figure 6. Comparative analysis of perceived usefulness, attitude, and flow with machine learning techniques. 


\subsection{Evaluation}

The evaluation is done among three parameters: perceived usefulness, attitude, and flow over behavior intention. The logistic regression prediction outperforms, i.e., 88.67\%, the other, which is $81.33 \%$ for SVM and $61.45 \%$ for ridge regression, in terms of perceived usefulness over BI. Similarly, logistic regression again gives better results in terms of attitude and flow, as shown in Table 8 . Hence, all three parameters provide high impact on behavior intention as per calculated results with TAM model and machine learning. Out of which perceived usefulness parameter is the most important, among all others. The training and testing accuracy for logistic regression model, SVM model and ridge regression is shown in Figures 7-9, respectively. For further analysis of models, receiver operating characteristic (ROC) curve is also calculated. Figures 10-12 represents the ROC curve for the logistic regression, SVM model, and ridge regression model, respectively.

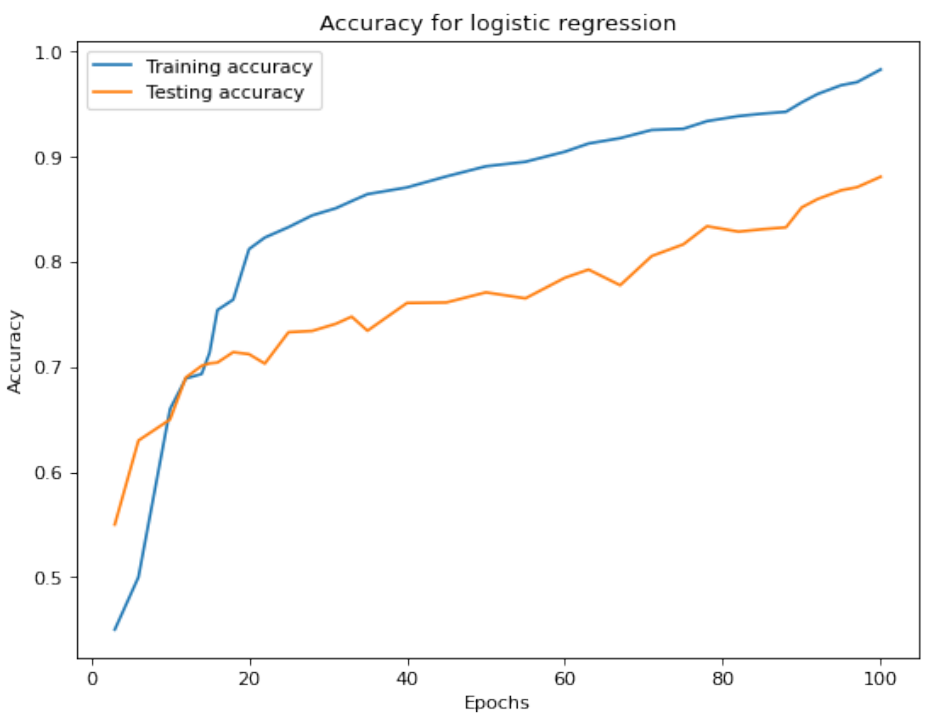

Figure 7. The accuracy for training and testing of logistic regression model.

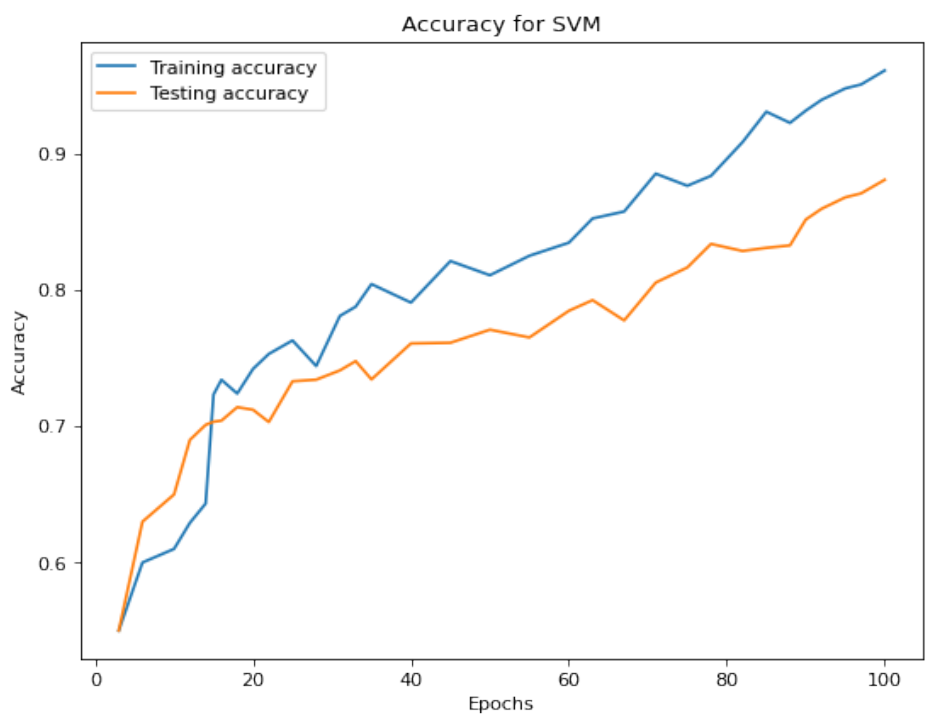

Figure 8. The accuracy for training and testing of SVM model. 


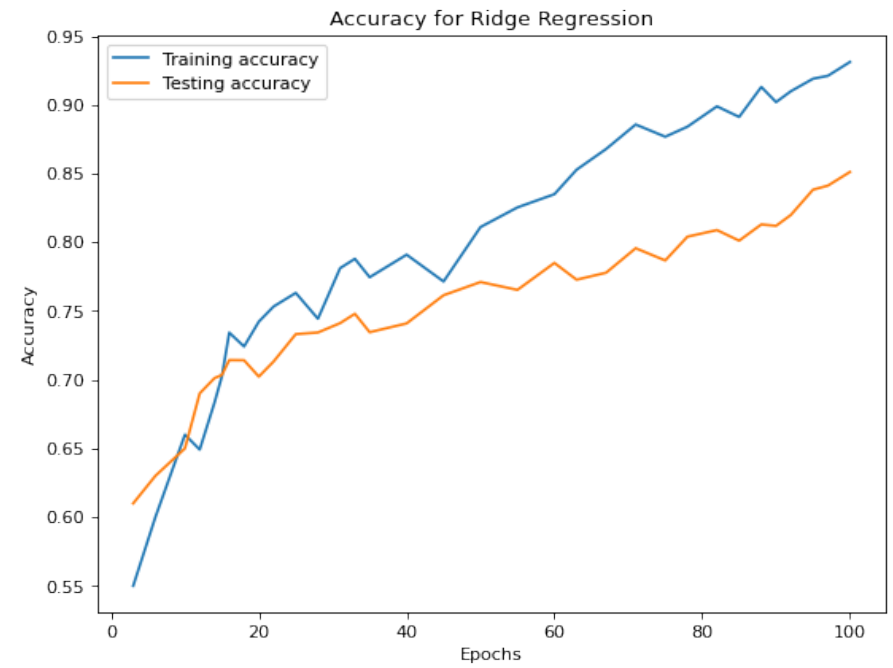

Figure 9. The accuracy for training and testing of ridge regression model.

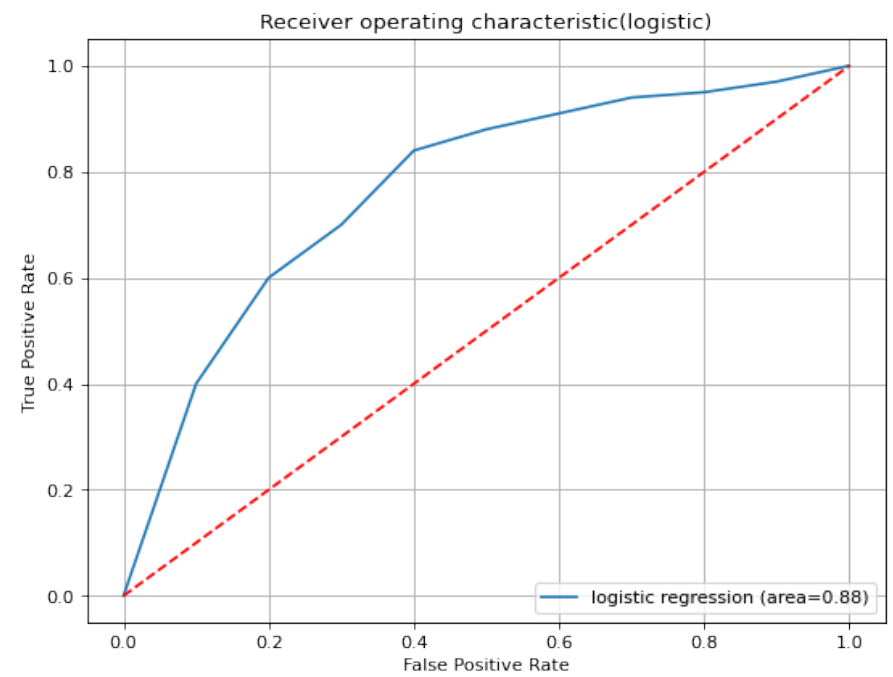

Figure 10. The ROC curve for logistic regression model.

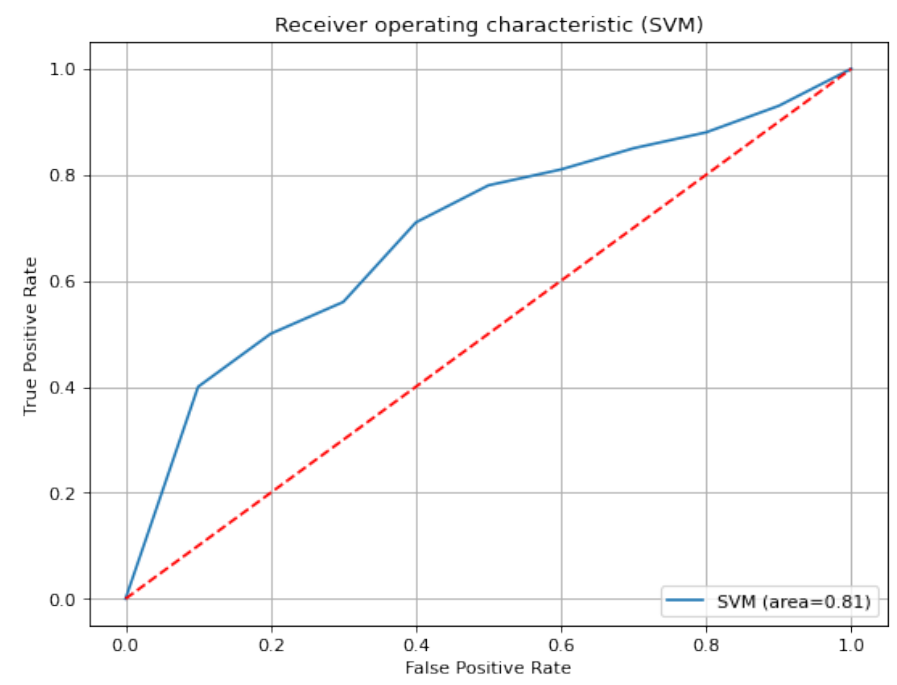

Figure 11. The ROC curve for SVM model. 


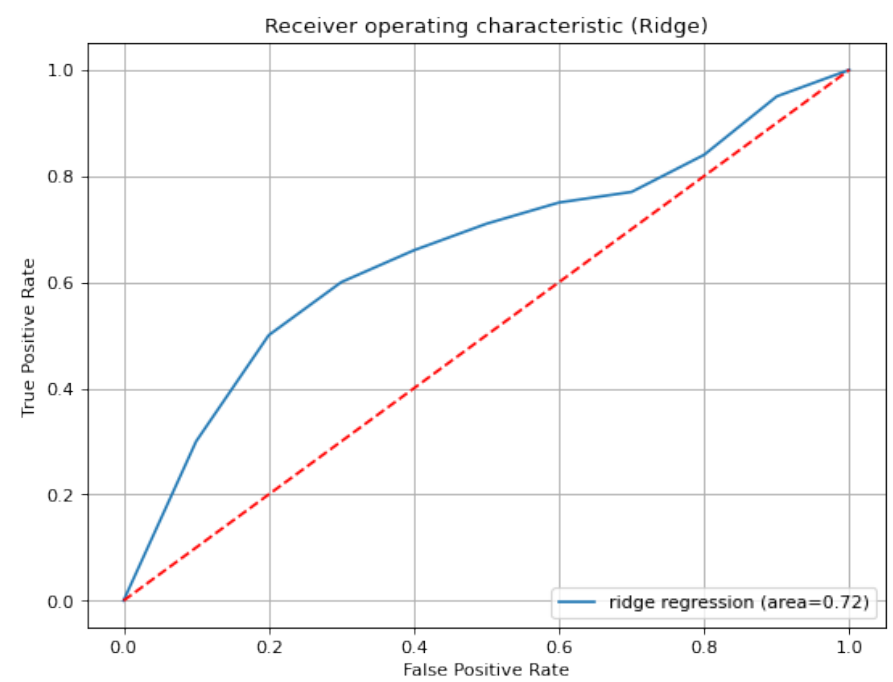

Figure 12. The ROC curve for ridge regression model.

Table 8. Comparative result of perceived usefulness, attitude, and flow.

\begin{tabular}{cccc}
\hline & PU (\%) & Attitude(\%) & Flow(\%) \\
\hline Logistic & 88.67 & 77.12 & 66.33 \\
SVM & 81.33 & 73.88 & 62.85 \\
Ridge & 61.45 & 54.99 & 48.90 \\
\hline
\end{tabular}

Table 9. Calculation of accuracy, recall, precision, and F1-score.

\begin{tabular}{ccccc}
\hline & Precision & Recall & F1 & Accuracy \\
\hline Logistic & 83.41 & 88.72 & 86.17 & 89.0 \\
SVM & 80.48 & 87.11 & 82.66 & 87.34 \\
Ridge & 60.55 & 62.05 & 61.13 & 62.12 \\
\hline
\end{tabular}

\section{Discussion and Limitation}

\subsection{Discussion}

This research found a conceptual model with the base of technology acceptance model which examined the SEM analysis on projected conceptual model for online games adoption. The research model was prepared with the support of previous studies related to online games $[28,29,64,69]$. The empirical-based finding was conducted in the study. The outcome of study is majorly focused on individual behavior, symmetry in relations between responses, intention, understanding, and attitude towards various online games available on the Internet. The data of the research was good fit in nature. Therefore, the data was best suitable for measurements, and the result of the theoretical model was supportive, which justifies accurate results related to people's behavior who are using online games or having a habit to play online games. The study reveals a symmetric relationship among the constructs. Therefore, the result found that symmetric social interaction has a positive significant impact on use context and perceived enjoyment. The outcome of this relationship is supported by Reference [70]. Another relation, i.e., use context, has found to have an impeccable effect on perceived enjoyment and perceived ease of use, which is supported by Reference [57]. Perceived ease of use is also found positive impact on perceived usefulness. Hence, results reinforced by previous study [38]. Next, perceived enjoyment reveal optimistic significant symmetric relationship with flow while playing online game. On the other hand, it is insignificant in relation to perceived usefulness and attitude, but results are supported by many researchers, whereby perceived usefulness has a substantial impact on attitude. The last relation of this study is with the dependent variable, i.e., behavior intention, in which the study found the positive relation to attitude, flow, 
and perceived usefulness, when comparing our observations with other literature work. Therefore, it can be implied that, in the field of online games, the study demonstrates that young consumers like to play online games frequently because they feel it easy, convenient, joyful, fun, and enjoyable, anytime and anywhere, without any performance consequences and trouble. The TAM model is very good in the implementation of quantitative problem of statistical analysis. For further evaluation machine learning approach is implemented to trigger the most prominent parameters indulge in the evaluation of online games complex problem. From this, three popular approaches are considered, i.e., logistic regression, ridge regression, and support vector machine. All these are worked efficiently to solve these kinds of problems. From Figures 7-9, the performance of the models over the dataset is shown. These figures elaborates the training and testing accuracy on the dataset. Similarly, the ROC curve is also calculated that provide the region area to give the performance. The higher the region in ROC curve that better will be the model. The ROC curve is represented in the Figures 10-12. Along with this, Table 9 gives the detailed view of performance in terms of Precision, Recall, F1-Score, and Accuracy. From all these most prominent factors evaluated is perceived usefulness, attitude, and flow, which affect high performance the most. Hence, the significance to apply machine learning approach is to reveal the most affective factors for online mobile games. Social interaction is also increased with this as most of the games on mobile devices are multiplayer games, where you can play with your friends, as well as strangers. They give the option to invite your friends via other social platforms, such as Facebook, WeChat, etc. This is how online games are also enhancing social interaction. The symmetry of social media platforms is reliable in providing services to the user. Each social media platform gains popularity only when there are a lot of things to do, i.e., interaction with people with friends, as well as strangers. The privacy of these platforms is also maintained at the individual level.

\subsection{Limitations}

Along with the positive aspects and relation among the constructs, there are some limitations in the existing study, which are supportive for the expected effort. Firstly, the data was only collected from India. Secondly, the focus of this study is only Internet games as the study recommends consideration of online mobile games, which gives more insight to the game developer for more innovation. Thirdly, in this research, the data was collected from a group of 16- to 35-year-old individuals, although the study suggests considering data of those above 35 years old because, in many regions, online games are very popular in the beyond 35 years old age group. However, the findings might not be possible to generalize, but it would be interesting to expand this research work to a global scale, as well as even explore other social media platforms to find symmetric relations between different considered factors.

\section{Conclusions}

This research provides an in-depth analysis of online games popularity in India. The theoretical model of this study is framed on the basis of cases analyses factors affecting online games and employed TAM theory. This research is based on 304 respondents, with 8 factors which are important for considering online games. We identified important constructs' symmetric relationship on behavioral intention with reference to online games and found that social interaction, use context, perceived ease of use, perceived enjoyment, perceived usefulness, attitude, flow, and behavior intention have a positive relationship with their relation to constructs, but, on the other hand, perceived enjoyment was insignificant in relations with perceived usefulness and attitude. This study provides a better understanding of adoption behavior and helps the game developer to improve better services. Specifically, Tables 7 and 8 results justify that PU, attitude, and flow are the most important factors for the study and engraved popularity for online gaming. Figures 7-9 give insight to the performance for the training and testing for the dataset. Similarly, Figures 10-12 represents the ROC curve for the dataset. According to the machine learning approaches, it 
is well defined that perceived usefulness, attitude, and flow are the more important factors that affect the model. It is clear from the analysis that perceived usefulness is the most prominent factor for online gaming industry. Hence, this study concludes that successful online mobile games will also make substantial efforts to deliver entertaining games in a widely obtainable manner and give well defined symmetry to the users. In the future, we will evaluate our concept on various models and other approaches. Further, we will go in-depth on the privacy factors for online mobile games.

Author Contributions: Conceptualization, S.C. and M.M.; methodology, M.M.; software, M.M.; validation, M.M. and M.W.; formal analysis, M.W. and S.G.; investigation, M.M.; resources, R.P.d.P.; data curation, S.C. and S.G.; writing-original draft preparation, S.C. and M.M.; writing-review and editing, M.M. and S.C.; visualization, R.P.d.P.; supervision, M.M. and M.W.; project administration, M.M.; funding acquisition, M.W. All authors have read and agreed to the published version of the manuscript.

Funding: The authors acknowledge contribution to this project from the Rector of Silesian University of Technology, Gliwice, Poland under the proquality grant no. 09/020/RGJ21/0007.

Institutional Review Board Statement: Not applicable.

Informed Consent Statement: Not applicable.

Conflicts of Interest: The authors declare no conflict of interest.

\section{References}

1. Mittal, M.; Kumar, K. Network Lifetime Enhancement of Homogeneous Sensor Network Using ART1 Neural Network. In Proceedings of the International Conference on Computational Intelligence and Communication Networks, Bhopal, India, 14-16 November 2014; pp. 472-475.

2. Chauhan, S.; Banerjee, R.; Mittal, M. An Analytical Study On Impluse Buying For Online Shopping during COVID-19. J. Content Community Commun. 2020, 12, 198-209. [CrossRef]

3. Mittal, M. Performance Evaluation of Cryptographic Algorithms. Int. J. Comput. Appl. 2012, 41, 1-6. [CrossRef]

4. Mittal, M.; Iwendi, C. A Survey on Energy-Aware Wireless Sensor Routing Protocols. Eai Endorsed Trans. Energy Web 2019, 6, 1-16. [CrossRef]

5. Mittal, M.; Siriaraya, P.; Lee, C.; Kawai, Y.; Yoshikawa, T.; Shimojo, S. Accurate Spatial Mapping of Social Media with Physical Locations. IEEE BSD Big Data 2019. [CrossRef]

6. Aljumaili, M.R.M.; Friesen, M. Serious Games and ML for Detecting MCI. In Proceedings of the IEEE Global Conference on Signal and Information Processing (GlobalSIP), Ottawa, ON, Canada, 11-14 November 2019; pp. 1-5.

7. Mittal, M.; Iwendi, C.; Khan, S.; Rehman, J.A. Analysis of security and energy efficiency for shortest route discovery in low-energy adaptive clustering hierarchy protocol using Levenberg-Marquardt neural network and gated recurrent unit for intrusion detection system. Trans. Emerg. Telecommun. Technol. 2020, 32, e3997. [CrossRef]

8. Mittal, M.S.; Srinivasan, M.R.; Vyas, O.P. Type-2 fuzzy ontology-based multi-agents system for wireless sensor network. In Proceedings of the TENCON 2017-2017 IEEE Region 10 Conference, Penang, Malaysia, 5-8 November 2017; pp. $2864-2869$. [CrossRef]

9. Wang, Y.; Siriaraya, P.; Mittal, M.; Xie, H.; Kawai, Y. Understanding Multilingual Correlation of Geo-Tagged Tweets for POI Recommendation. In Proceedings of the International Symposium on Web and Wireless Geographical Information Systems, Wuhan, China, 13-14 November 2020; Volume 12473, pp. 2864-2869.

10. Mittal, M.L.K.; Saraswat, C.I.; Anajemba, J.H. A Neuro-Fuzzy Approach for Intrusion Detection in Energy Efficient Sensor Routing. In Proceedings of the 4th International Conference on Internet of Things: Smart Innovation and Usages (IoT-SIU), Ghaziabad, India, 18-19 April 2019; pp. 1-5.

11. Mittal M.K.S. Performance Evaluation of LEACH Protocol Based on Data Clustering Algorithms. In Proceedings of the 2nd International Conference on Communication, Computing and Networking, Chandigarh, India, 29-30 March 2019.

12. Gupta, S.M.M.; Padha, A. Predictive Analytics of Sensor Data Based on Supervised Machine Learning Algorithms. In Proceedings of the 2017 International Conference on Next Generation Computing and Information Systems (ICNGCIS), Jammu, India, 11-12 December 2017; pp. 171-176.

13. Mittal, M.; Vijayal, S. Detection of attacks in IoT based on ontology using SPARQL. In Proceedings of the 7th International Conference on Communication Systems and Network Technologies (CSNT), Nagpur, India, 11-13 November 2017; pp. 206-211.

14. Brown, J.A.; Cuzzocrea, A.; Kresta, M.; Kristjanson, K.D.; Leung, C.K.; Tebinka, T.W. A Machine Learning Tool for Supporting Advanced Knowledge Discovery from Chess Game Data. In Proceedings of the IEEE International Conference on Machine Learning and Applications (ICMLA), Cancun, Mexico, 18-21 December 2017; pp. 649-654. 
15. Cardamone, L.D.L.; Lanzi, P.L. Learning to Drive in the Open Racing Car Simulator Using Online Neuroevolution. IEEE Trans. Comput. Intell. Games 2010, 2, 176-190. [CrossRef]

16. Tavakoli, S.; Yooseph, S. Learning a mixture of microbial networks using minorization-maximization. Bioinformatics 2019, 35, 123-130. [CrossRef]

17. Jahanshahi, A. TinyCNN: A Tiny Modular CNN Accelerator for Embedded FPGA. arXiv 2019, arxiv:1911.06777.

18. Roshani, M. Evaluation of flow pattern recognition and void fraction measurement in two phase flow independent of oil pipeline's scale layer thickness. Alex. Eng. J. 2021. [CrossRef]

19. Voghoei, S.; Tonekaboni, N.H.; Yazdansepas, D.; Arabnia, H.R. University Online Courses: Correlation between Students' Participation Rate and Academic Performance. In Proceedings of the International Conference on Computational Science and Computational Intelligence, Las Vegas, NV, USA, 5-7 December 2019; pp. 772-777.

20. Roshani, M.; Phan, G.; Faraj, R.H.; Phan, N.H.; Roshani, G.H.; Nazemi, B.; Corniani, E.; Nazemi, E. Proposing a gamma radiation based intelligent system for simultaneous analyzing and detecting type and amount of petroleum by-products. Nucl. Eng. Technol. 2021, 53, 1277-1283. [CrossRef]

21. Chauhan, S.; Banerjee, R.; Chakraborty, C.; Mittal, M.; Shiva, A.; Ravi, V. A self-congruence and impulse buying effect on user's shopping behaviour over social networking sites: An empirical study. Int. J. Pervasive Comput. Commun. 2021. [CrossRef]

22. Baykal, O.; Alpaslan, F.N. Supervised Learning in Football Game Environments Using Artificial Neural Networks. In Proceedings of the International Conference on Computer Science and Engineering (UBMK), Chiang Mai, Thailand, 21-24 November 2018; pp. 110-115.

23. Persio, L.; Garbelli, M. Deep Learning and Mean-Field Games: A Stochastic Optimal Control Perspective. Symmetry 2021, 13, 14. [CrossRef]

24. Cornel, J.A.; Pablo, C.C.; Marzan, J.A.; Mercado, V.J.; Fabito, B.; Rodriguez, R.; Octaviano, M.; Oco, N.; De La Cruz, A. Cyberbullying Detection for Online Games Chat Logs using Deep Learning. In Proceedings of the 11th International Conference on Humanoid, Nanotechnology, Information Technology, Communication and Control, Environment, and Management (HNICEM), Laoag, Philippines, 29 November-1 December 2019; pp. 1-5.

25. Bălan, O.; Moise, G.; Petrescu, L.; Moldoveanu, A.; Leordeanu, M.; Moldoveanu, F. Emotion Classification Based on Biophysical Signals and Machine Learning Techniques. Symmetry 2020, 12, 21. [CrossRef]

26. Ren, X.; Li, L.; Yu, Y.; Xiong, Z.; Yang, S.; Du, W.; Ren, M. A Simplified Climate Change Model and Extreme Weather Model Based on a Machine Learning Method. Symmetry 2020, 12, 139. [CrossRef]

27. Cheong, Y.G.; Jensen, A.K.; Guðnadóttir, E.R.; Bae, B.C.; Togelius, J. Detecting Predatory Behavior in Game Chats. IEEE Trans. Comput. Intell. Games 2015, 7, 220-232. [CrossRef]

28. Shin, D.H.; Shin, Y.J. Why do people play social network games? Comput. Hum. Behav. 2011, 27, 852-861. [CrossRef]

29. Lin, T.H.; Lu, H.P.; Hsu, H.H.; Hsing, S.S.; Ho, T.L. Why do people continue to play social network game (SNG)? An empirical study by social and emotional perspectives. Int. J. E-Adopt. 2013, 5, 22-35. [CrossRef]

30. Davis, F. Perceived usefulness, perceived ease of use, and user acceptance of information technology. MIS Q. 1989, 13, 319-340. [CrossRef]

31. Davis, F.D.; Bagozzi, R.P.; Warshaw, P.R. Extrinsic and intrinsic motivation to use computers in the workplace. J. Appl. Soc. Psychol. 1992, 22, 1111-11323. [CrossRef]

32. Fishbein, M.; Ajzen, I. Belief, Attitude, Intention, and Behavior: An Introduction to Theory and Research; Addison-Wesley: New York, NY, USA, 1975. [CrossRef]

33. Thompson, R.L.; Higgins, C.A.; Howell, J.M. Personal computing: toward a conceptual model of utilization. MIS Q. 1991, 15, 125-143. [CrossRef]

34. Ajzen, I. The theory of planned behavior. Organ. Behav. Hum. Decis. Process. 1991, 50, 179- 211. [CrossRef]

35. Venkatesh, V.M.G.; Morris, G.B.D.; Davis, F.D. User acceptance of information technology: toward a unified view. MIS Q. 2003, 27, 425-478. [CrossRef]

36. Davis, F.D.; Bagozzi, R.P.; Warshaw, P.R. User acceptance of computer technology: A comparison of two theoretical models. Manag. Sci. 1989, 35, 982-1003. [CrossRef]

37. Connolly, T.M.; Boyle, E.A.; MacArthur, E.; Hainey, T.; Boyle, J.M. A systematic literature review of empirical evidence on computer games and serious games. Comput. Educ. 2012, 59, 661-686. [CrossRef]

38. Wang, Q.; Sun, X. Investigating gameplay intention of the elderly using an extended technology acceptance model (ETAM). Technol. Forecast. Soc. Chang. 2016, 107, 59-68. [CrossRef]

39. Hsu, C.L.; Lu, H.P. Why do people play on-line games? An extended TAM with social influences and flow experience. Inf. Manag. 2004, 41, 853-868. [CrossRef]

40. Lee, M.C. Understanding the behavioural intention to play online games: An extension of the theory of planned behaviour. Online Inf. Rev. 2009, 33, 849-872. [CrossRef]

41. Wu, J.; Liu, D. The effects of trust and enjoyment on intention to play online games. J. Electron. Commer. Res. 2007, 8, 128-140.

42. Choi, D.; Kim, J. Why people continue to play online games: In search of critical design factors to increase customer loyalty to online contents. Cyberpsychol. Behav. 2004, 7, 11-24. [CrossRef]

43. van de Wijngaert, L.; Bouwman, H. Would you share? Predicting the potential use of a new technology. Telemat. Inform. 2009, 26, 85-102. [CrossRef] 
44. Mallat, N. Exploring consumer adoption of mobile payments-A qualitative study. J. Strateg. Inf. Syst. 2007, 16, 413-432. [CrossRef]

45. Legris, P.J.I.; Collerette, P. Why do people use information technology? A critical review of the technology acceptance model. Inf. Manag. 2003, 40, 191-204. [CrossRef]

46. Doll, J.; Ajzen, I. Accessibility and stability of predictors in the theory of planned behavior. J. Personal. Soc. Psychol. 1992, 63, 754-765. [CrossRef]

47. van der Heijden, H. Factors influencing the usage of websites: The case of a generic portal in The Netherlands. Inf. Manag. 2003, 40, 541-549. [CrossRef]

48. Ha, I.; Yoon, Y.; Choi, M. Determinants of adoption of mobile games under mobile broadband wireless access environment. Inf. Manag. 2007, 44, 276-286. [CrossRef]

49. Csikszentmihalyi, M.; Csikszentmihalyi, I. Optimal Experience: Psychological Studies of Flow in Consciousness; Cambridge University Press: Cambridge, UK, 2000.

50. Lu, Y.T.Z.; Wang, B. Exploring Chinese users' acceptance of instant messaging using the theory of planned behavior, the technology acceptance model, and the flow theory. Comput. Hum. Behav. 2009, 25, 29-39. [CrossRef]

51. Csikszentmihalyi, M.; LeFevre, J. Optimal experience in work and leisure. J. Personal. Soc. Psychol. 1989, 56, 815-822. [CrossRef]

52. Ghani, J.A. Human factors in information systems. In Flow in Human-Computer Interactions: Test of a Model; Carey, J.M., Ed.; Ablex Publishing Corp.: Norwood, NJ, USA, 1995; pp. 291-311.

53. Li, D.; Browne, G.J. The role of need for cognition and mood in online flow experience. J. Comput. Inf. Syst. 2006, $46,11-17$.

54. Moon, J.W.; Kim, Y.G. Extending the TAM for a worldwide- web context. Inf. Manag. 2001, 38, 217-230. [CrossRef]

55. Liu, Y.; Li, H. Exploring the impact of use context on mobile hedonic services adoption: An empirical study on mobile gaming in China. Comput. Hum. Behav. 2011, 27, 890-898. [CrossRef]

56. Trepte, S.L.R.; Juechems, K. The social side of gaming: How playing online computer games creates online and offline social support. Comput. Hum. Behav. 2012, 28, 832-839. [CrossRef]

57. Rauniar, R.; Rawski, G.; Yang, J.; Johnson, B. Technology acceptance model (TAM) and social media usage: An empirical study on Facebook. J. Enterp. Inf. Manag. 2014, 27, 6-30. [CrossRef]

58. Sharma, S.; Mukherjee, S.; Kumar, A.; Dillon, W.R. A simulation study to investigate the use of cutoff values for assessing model fit in covariance structure models. J. Bus. Res. 2005, 58, 935-943. [CrossRef]

59. MacCallum, R.C.; Browne, M.W.; Sugawara, H.M. Power Analysis and Determination of Sample Size for Covariance Structure Modeling. Psychol. Methods 1996, 1, 130-149. [CrossRef]

60. Hu, L.; Bentler, P. Cutoff Criteria for Fit Indexes in Covariance Structure Analysis: Conventional Criteria Versus New Alternatives. Struct. Equ. Model. 1999, 6, 1-55. [CrossRef]

61. Klem, L. Structural equation modeling. In Using Multivariate Statistics, 5th ed.; Tabachnick, B.G., Fidell, L.S., Eds.; Pearson Education Inc.: Boston, MA, USA,1996; pp. 676-780.

62. Miles, J.; Shevlin, M. A time and a place for incremental fit indices. Personal. Individ. Differ. 2007, 42, 869-874. [CrossRef]

63. McDonald, R.; Ho, M.H. Principles and Practice in Reporting Statistical Equation Analyses. Psychol. Methods 2002, 7, 64-82. [CrossRef] [PubMed]

64. Park, E.; Baek, S.; Ohm, J.; Chang, H.J. Determinants of player acceptance of mobile social network games: An application of extended technology acceptance model. Telemat. Inform. 2014, 31, 3-15. [CrossRef]

65. Jiang, Y.J.J.; Palmer, I.J. Computerized Interactive Gaming via Supporting Vector Machines. Int. J. Comput. Games Technol. 2008, 1-7. [CrossRef]

66. Yun, H. Using Logistic Regression to Analyze the Balance of a Game: The Case of StarCraft II. arXiv 2011, arXiv:1105.0755.

67. Zekić-Sušac, M.; Nataša Šarlija, A.H.; Bilandžić, A. Predicting company growth using logistic regression and neural networks. Croat. Oper. Res. Rev. 2016, 7, 229-248. [CrossRef]

68. Lipovetsky, S.; Conklin, M. Analysis of regression in game theory approach. Appl. Stochastic Models Bus. Ind. 2001, 17, 319-330. [CrossRef]

69. Ding, Y.Y.Z.; Kankanhalli, A. Why do I invite friends to join: An empirical study of mobile social network game. In Proceedings of the 18th Pacific Asia Conference on Information Systems, Chengdu, China, 24-28 June 2014.

70. Raman, P. Examining the importance of gamification, social interaction and perceived enjoyment among young female online buyers in India. Young Consum. 2020. [CrossRef] 